\title{
Hydrogen Induced Crack Development in Submerged Arc Welded Steel Pipes
}

\author{
Marianthi Bouzouni ${ }^{1,2 *}$,Evangelos Gavalas ${ }^{1,2}$, Filippos Chatzigeorgiou ${ }^{1}$, Spyros \\ Papaefthymiou ${ }^{1}$ \\ ${ }^{1}$ National Technical University of Athens, School of Mining \& Metallurgical Engineering, Division \\ of Metallurgy and Materials, Laboratory of Physical Metallurgy, 9, Her. Polytechniou str., Zografos, \\ GR-157 80, Athens, Hellas \\ ${ }^{2}$ ELKEME S.A., 56th km Athens-Lamia Nat. Road, 32011 Oinofyta, Viotia, Greece
}

\begin{abstract}
The current work examines hydrogen sensitivity in different pipeline steels (X65, X70 and X80 HSLA grades) from four productions. Hydrogen Induced Cracking (HIC) experiments were performed and then the welds were characterized via optical and scanning electron microscopy techniques. The optical micrographs revealed cracks only in one of the four welds. Transverse cracks were found along bainitic-ferrite/carbide islands within the heat affected zone and the base metal of production B. Found inclusions e.g. MnS inside the cracks acted as initiation points for the HIC. However, the weld zones in all productions consisting of acicular ferrite and grain boundary ferrite were found to be resistant in hydrogen embrittlement. Therefore, the presence of bainitic ferrite with carbides at the grain boundaries in the microstructures and the intense presence of $\mathrm{MnS}$ inclusions caused HIC in pipeline steel from production B. The manufacturing process, the forming and welding conditions in the examined case seem not to have negatively influenced the pipeline steel in terms of HIC.
\end{abstract}

\section{Introduction}

The increase in demand of oil and gas leads manufacturers to use High Strength Low Alloyed steels (HSLA) which have an ideal combination of formability, weldability, yield strength and low cost. However, oil and gas contain small amount of hydrogen sulfide $\left(\mathrm{H}_{2} \mathrm{~S}\right)$, which may cause hydrogen embrittlement through hydrogen induced cracking (HIC) or other embrittlement mechanisms. It is well known that HIC is one of the major reasons of pipeline steel failures under sour service conditions. A corrosion reaction on the steel's surface causes the diffusion of atomic hydrogen into the steel lattice, where it can be trapped into reversible (e.g. dislocations or grain boundaries) or irreversible traps (e.g. inclusions). The atomic hydrogen recombines into molecular at inclusions and imperfections in the steel matrix. The formation of $\mathrm{H}_{2}$ gas is accompanied by substantial pressure of thousand megapascals, which cause significant damage mechanisms [1], [2].

* Corresponding author: mbouzouni@elkeme.vionet.gr 
The simplest type of hydrogen embrittlement is HIC. It can occur without external stresses and is commonly found in steels with high impurity levels. HIC can produce surface blisters and/or internal cracks. When atomic hydrogen diffuses into the steel matrix, it migrates to high stress areas or remains in the interstitial lattice sites [3]. The hydrogen traps, as mentioned before, can be reversible or irreversible depending on the binding energy for the hydrogen atoms [4]. If a trap has very high binding energy, it will be very difficult for an $\mathrm{H}^{+}$atom to escape from a trap and, therefore, it can be considered as irreversible. Grain boundaries and dislocations are bifunctional traps, proven by the contradictory experimental results on $\mathrm{H}^{+}$diffusion [5]. Non-metallic inclusions (oxides, sulfides) and precipitates are considered as strong irreversible traps for $\mathrm{H}^{+}$. Grain boundaries can either increase the $\mathrm{H}^{+}$diffusion rate, as they act like high diffusivity paths increasing $\mathrm{H}^{+}$mobility, or decrease it by trapping $\mathrm{H}^{+}$. Grain size is another parameter that affects HIC susceptibility. As the grain size decreases, the mobility of $\mathrm{H}^{+}$increases (larger grain boundary area per unit volume). On the contrary, the higher density of junction points (more interfaces in finer microstructure) act as potential traps that can lead to the reduction of $\mathrm{H}^{+}$mobility. Thus, the maximum $\mathrm{H}^{+}$diffusion is found at an optimum grain size [4]. According to $[6,7]$, the efficiency of trapping tends to increase in the following order: small second phase particles, coarse pearlite, fine pearlite, bainite and martensite. It is concluded that the martensite/austenite $(\mathrm{M} / \mathrm{A})$ constituents, the $\mathrm{Fe}_{3} \mathrm{C}$ interfaces and the pearlite banding are the most crucial parameters that affect HIC susceptibility. Acicular ferrite is a HIC resistant microstructure [6, 8-10]. The high toughness and high $\mathrm{H}-$ trapping efficiency are ascribed to its typically fine grain size and the absence of iron carbide precipitates. Titanium (Ti) encourages the nucleation of acicular ferrite (AF) and increases the ductility of the weld metal [9]. Bainitic microstructures containing cementite laths and martensite/austenite (M/A) constituents increase the HIC susceptibility. The accumulation of significant amount of $\mathrm{H}^{+}$concentration at the bainitic lath boundaries can eventually lead to the separation of these interfaces (cracks), when the $\mathrm{H}^{+}$concentration reaches a critical value [11]. Granular bainite forms at relatively high temperatures. By increasing the cooling rate after the weld or the post heat treatment, finer bainitic ferrite $(\mathrm{BF})$ with finer $\mathrm{M} / \mathrm{A}$ islands can be formed. This product has higher dislocation density and higher strength comparing with high temperature ferrite [4]. Since the steel microstructure derives as combination of its chemical composition and the applied thermomechanical process steps, the role of the alloying elements and the understanding of their effect in the microstructure formation is crucial. Alloying elements such as carbon (C) and manganese (Mn) should be kept low to avoid the tendency for segregation and thus the formation of phases sensitive to HIC (e.g. MnS, Martensite, pearlite) [12],[13]. On the contrary carbide forming elements (e.g. Ti, $\mathrm{Nb}, \mathrm{Mo}$ ) at increased levels form nano-sized carbonitrides, which are harmless traps for $\mathrm{H}^{+}$since they impede their diffusion in the microstructure and their coupling with other $\mathrm{H}^{+}$atoms [14 -16]. The aim of the present study is to examine the susceptibility of HIC in the weld zones of steel pipes welded according to the Longitudinal Submerged Arc Welding (LSAW) method in usual LSAW pipeline productions that are not designed to resist in sour environments.

\section{Experimental Procedure}

The weld zones of twelve (12) HSLA steel specimens (length $130 \mathrm{~mm}$ and thickness $25 \mathrm{~mm}$ ) were examined from four different LSAW productions that were not designed to resist in sour environments. Table 1 show the characteristics and the chemical composition of the examined LSAW pipeline productions. Hydrogen induced cracking (HIC) test has been 
initially implemented to these samples according to the template of NACE TM $0284-2016$ [16]. Sample preparation usual for microscopy observation via optical (OM) and scanning electron microscopy (SEM) techniques was applied. This included cutting, shuttering, rough grinding, smooth grinding and chemical etching (Nital 4\%) according to the template NACE TM 0284 - 2016. The samples were examined first by optical microscopy, in which the microstructures and the found cracks including their dimensions (Image - Pro Plus v. 7.0.1.658) were carefully studied. Then the recognition of the inclusions inside found cracks followed via SEM-EDS (electron dispersive spectroscopy).

Table 1. Dimensions, grade and chemical compositions of the examined steels

\begin{tabular}{|c|c|c|c|c|c|c|c|c|c|c|}
\hline Production & Grade & $\begin{array}{c}\mathbf{O D}^{*} \\
(\mathbf{m m})\end{array}$ & $\begin{array}{c}\mathbf{W T}^{* *} \\
(\mathbf{m m})\end{array}$ & $\mathbf{C \%}$ & $\mathbf{S i} \%$ & $\begin{array}{c}\mathbf{M n} \\
\mathbf{\%}\end{array}$ & $\mathbf{P \%}$ & $\mathbf{S \%}$ & $\mathbf{N b \%}$ & $\mathbf{T i \%}$ \\
\hline A & $\mathrm{X} 80$ & 1219,2 & 30,0 & 0,063 & 0,19 & 1,82 & 0,0094 & 0,0008 & 0,038 & 0,013 \\
\hline B & X70 & 457,2 & 31,8 & 0,048 & 0,04 & 1,85 & 0,0065 & 0,0003 & 0,019 & 0,01 \\
\hline C & X65 & 914,4 & 22,9 & 0,061 & 0,25 & 1,48 & 0,0098 & 0,0009 & 0,036 & 0,015 \\
\hline D & X70 & 1219,2 & 21,0 & 0,056 & 0,25 & 1,57 & 0,0071 & 0,0005 & 0,037 & 0,017 \\
\hline
\end{tabular}

*OD: external diameter of the pipe

${ }^{* *}$ WT: width of the pipe

Moreover, the crack sensitivity ratio (CSR), crack length ratio (CLR) and crack thickness ratio (CTR) index were estimated to quantify the extent of HIC [17]. The expressions of CSR, CLR and CTR are as follows:

$\mathrm{CSR}=\sum(\mathrm{ab}) / \mathrm{WT} 100 \%$

$\mathrm{CLR}=\sum \mathrm{a} / \mathrm{W} 100 \%$

$\mathrm{CTR}=\sum \mathrm{b} / \mathrm{T} 100 \%$

Where a: crack length

b: crack width

W: specimen length

$\mathrm{T}$ : specimen thickness

The measurement of the cracks in each specimen is depicted in Figure 1. 


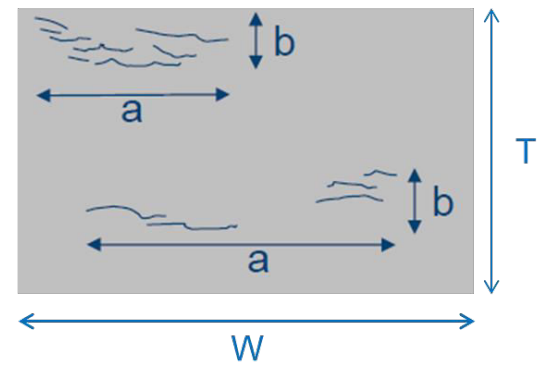

Fig. 1. Schematic representation of the crack measurement in the specimens.

\section{Results and Discussion}

\subsection{Microstructure of Weld Zones}

Figure 2 shows the optical micrographs of weld zone microstructure in the four productions. The microstructure is refined consisting mainly from Acicular Ferrite (AF), whereas Grain Boundary Ferrite (GBF) can be found surrounding the AF. Since the fine ferrite needles that compose AF do not facilitate the diffusion and accumulation of $\mathrm{H}^{+}$ atoms, no cracks appeared in the weld zones in all productions after the NACE test.
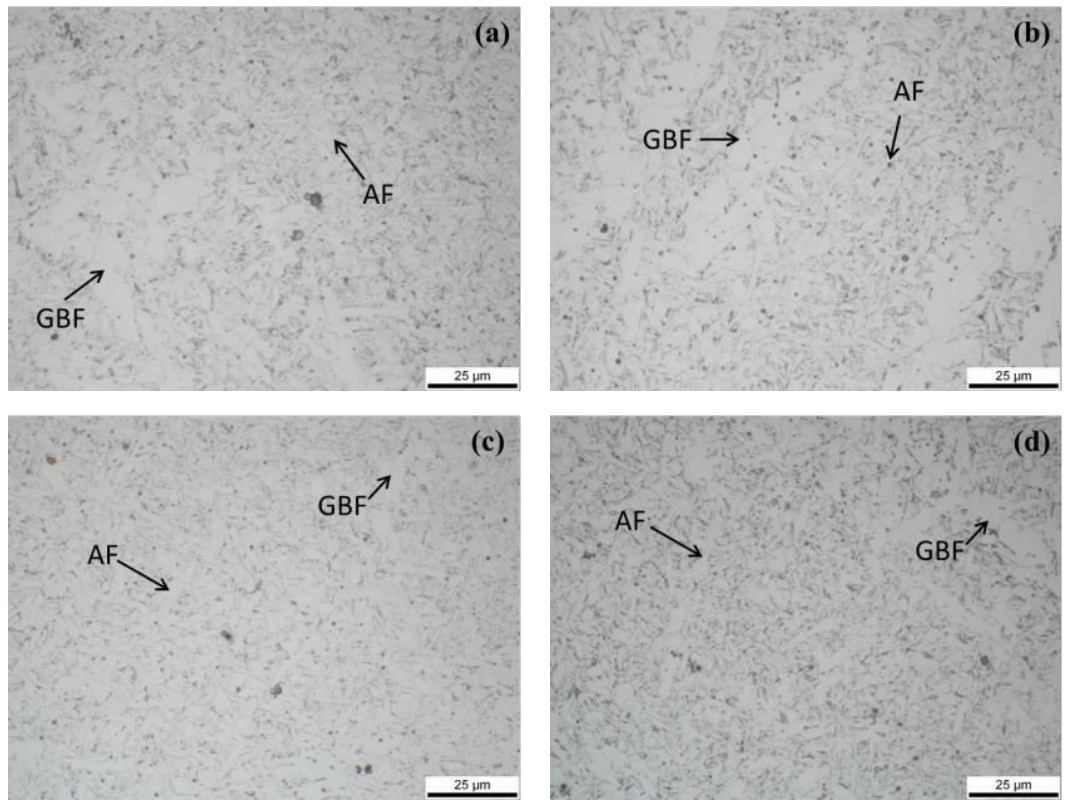

Fig. 2. Optical micrographs of microstructures of weld zones in production A (a), production $\mathrm{B}(\mathrm{b})$, production $\mathrm{C}(\mathrm{c})$ and production $\mathrm{D}(\mathrm{d})$

\subsection{Microstructure of Heat Affected Zones}


The microstructures of the heat affected zone of the steels from the four production sequences are depicted in Figure 3. In all productions, blocks of Bainitic Ferrite (BF) laths appeared in the heat affected zones (HAZ). It is extremely difficult to distinguish packets of BF separately in OM and even in SEM. Due to the different lath orientation the blocks of the BF laths it is possible in the OM and SEM to view the different BF blocks. Of course for a more detailed understanding of the microstructural features and their correlation with the HIC mechanism, higher electron microscopy techniques like transmission electron microscopy should be employed. Area of carbides (C) is also appeared next to bainitic ferrite. In production B, cracks appeared in the middle of the HAZ (Figure 3). The cracks cross the area between carbides and lath blocks of BF since in these points coherency is lost and accumulation of $\mathrm{H}^{+}$is facilitated. From SEM - EDS analysis carbo - nitrides $(\mathrm{Ti}, \mathrm{Nb}) \mathrm{CN}$ and $\mathrm{MnS}$ sulfides are the starting points for crack formation (Figure 4). In addition, Production B showed coarser BF laths, which means that it contained larger grain boundary area and in this way increased the mobility of $\mathrm{H}^{+}$.
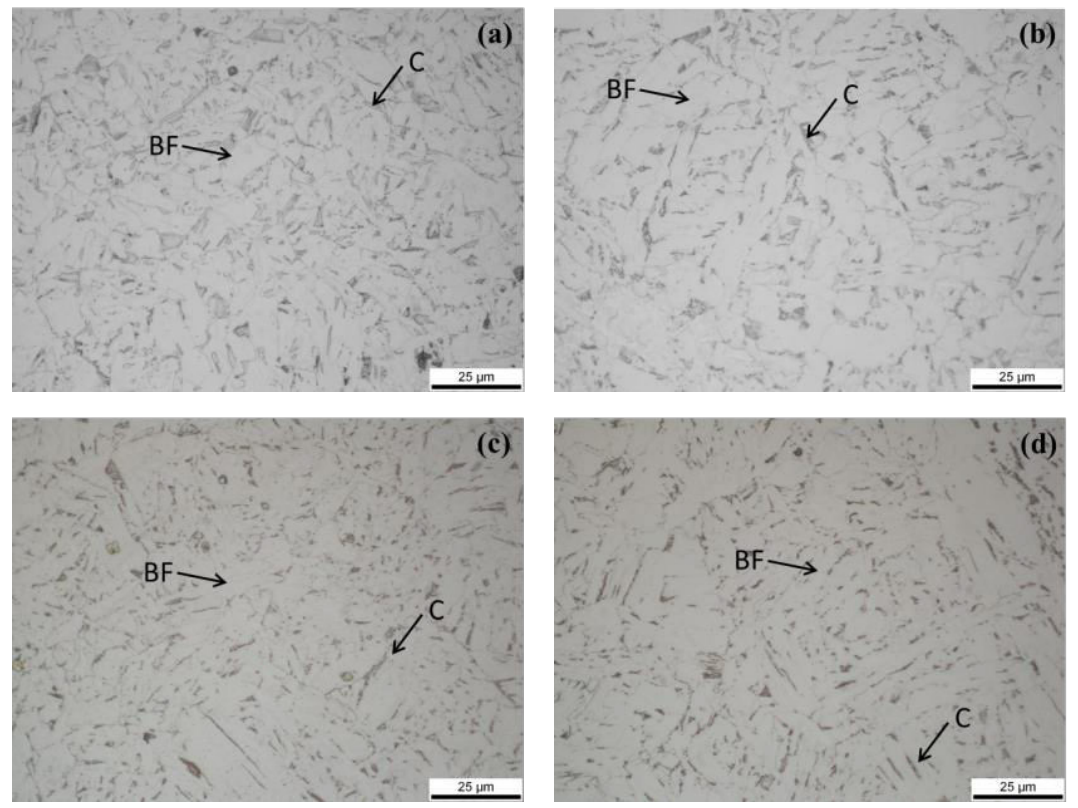

Fig. 3. Optical micrographs of microstructures of heat affected zones in Production A (a), Production B (b), Production C (c) and Production D (d)

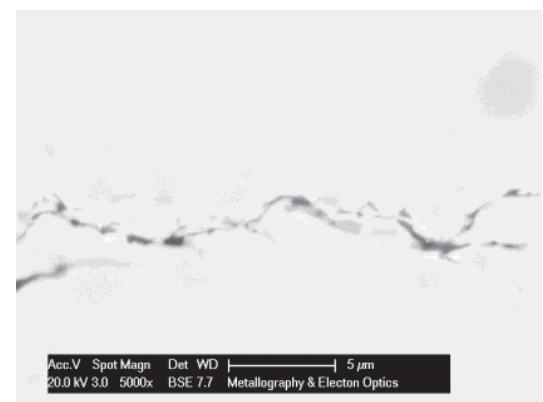

Fig. 4. SEM micrograph of crack appeared on the heat affected zone in Production B. 


\subsection{Microstructure of Base Metal}

The microstructures of base metals (BM) are shown in Figure 5. The microstructure in Production A and B is mainly Bainitic Ferrite (BF) and Carbides (C) whereas the microstructure in Productions $\mathrm{C}$ and D consists of Polygonal Ferrite (PF) and Granular Bainite (GB). The difference in microstructure is attributed to different Thermo-mechanical Controlled Processing (TMCP) and variation of the chemical composition. Productions A and $\mathrm{B}$ exhibit fine microstructures, whereas the appearance of $\mathrm{BF}$ indicates that probably the finish rolling temperatures were lower or that accelerated cooling was used after the final pass in TMCP. Moreover, Productions A and B exhibit increased manganese (Mn) content in comparison to productions $\mathrm{C}$ and $\mathrm{D}$. $\mathrm{Mn}$ is known for preventing the pearlite formation and depressing the austenite to $\mathrm{PF}$ transformation, thus, resulting in a more refined microstructure [18]. However, in production B, HIC appears in the middle of the $\mathrm{BM}$ parallel to the rolling direction (RD). SEM - EDS analysis revealed transverse cracks that were found inside of longitudinal $\mathrm{MnS}$ inclusions, aligned parallel to the RD (1 $8 \mu \mathrm{m}$ ), which acted as nucleation points for these cracks (Figure 6). The appearance of large $\mathrm{MnS}$ indicates intense centerline segregation of the steel grades from which the pipes were manufactured.
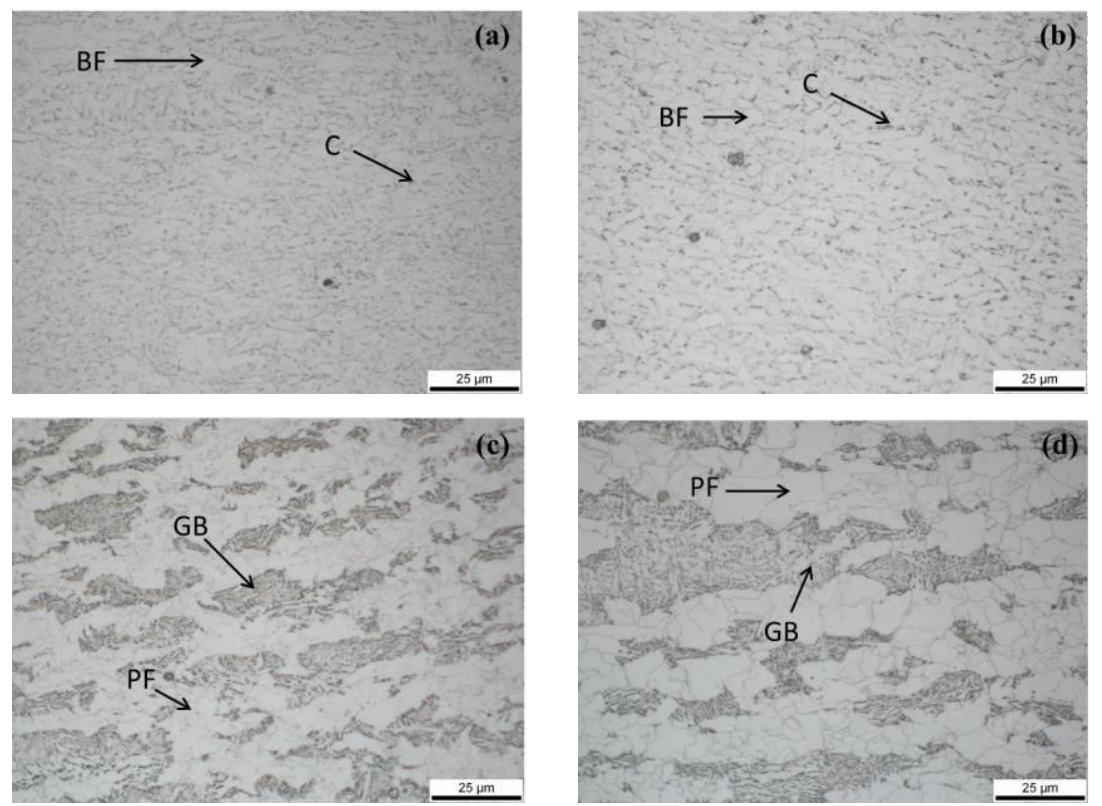

Fig. 5. Optical micrographs of microstructures of base metal in Production A (a), production $\mathrm{B}(\mathrm{b})$, production $\mathrm{C}(\mathrm{c})$ and production $\mathrm{D}(\mathrm{d})$ 


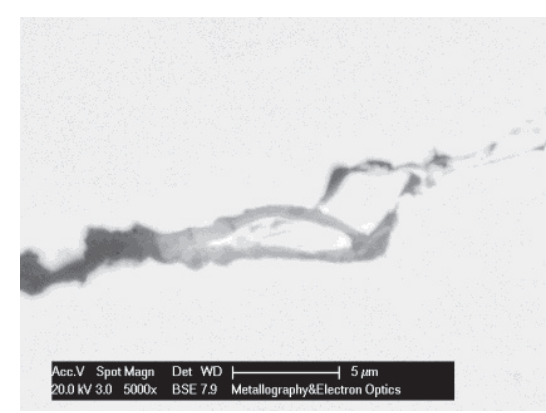

Fig. 6. SEM micrograph of crack appeared on the base metal in production B.

\subsection{Analysis of CSR, CLR and CTR Indexes}

Table 2 summarizes the results of CSR, CLR and CTR indexes. Only in production B the indexes are increased compared to the other productions especially the CLR which exceeds the maximum allowed limit [17]. The CLR index shows that extensive cracking parallel to rolling direction has occurred in pipeline steels of production $\mathrm{B}$ due to the presence of elongated inclusions which is in good correlation with the metallographic results (Figure 7). The elongated inclusions along with high density of dislocations created during bending led to HIC. The dislocations created more diffusional paths for $\mathrm{H}^{+}$atoms to diffuse and the inclusions operated as $\mathrm{H}^{+}$traps.

Table 2. Results for CSR, CLR and CTR index

\begin{tabular}{|c|c|c|c|}
\hline Production & $\begin{array}{c}\text { CSR } \\
\mathbf{\%}\end{array}$ & $\begin{array}{c}\text { CLR } \\
\mathbf{\%}\end{array}$ & $\begin{array}{c}\text { CTR } \\
\mathbf{\%}\end{array}$ \\
\hline A & 0,00 & 0,00 & 0,00 \\
\hline B & 0,471 & 20,91 & 2,25 \\
\hline C & 0,00 & 0,00 & 0,00 \\
\hline D & 0,00 & 0,00 & 0,00 \\
\hline $\max \leq$ & 2 & 15 & 5 \\
\hline
\end{tabular}

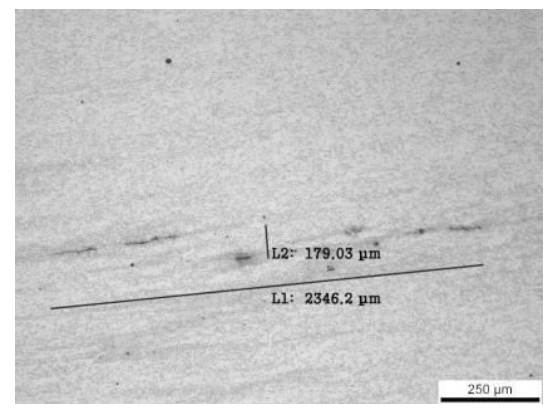

Fig. 7. Indicative optical micrograph of the crack measurement in production $B . L_{1}$ corresponds to the crack length while $\mathrm{L}_{2}$ corresponds to the crack thickness. 


\section{Conclusions}

As a conclusion to this work, the welds and HAZs from productions A, C and D were resistant to HIC as they did not show any hydrogen embrittlement after the NACE test. Therefore, the pipes from these productions are suitable for usage in sour environments. On the contrary, production B showed limited resistance to HIC as a result of its coarser microstructure of bainitic ferrite and carbides. Although the welds from LSAW productions that were not designed to resist HIC, the current results from the NACE test are extremely encouraging. Even thick LSAW pipes can resist effectively HIC. The increased Mn content led to high centreline segregation in the steel prior to pipe welding. Areas in the microstructure with increased Mn content formed MnS stringers, which act as permanent $\mathrm{H}^{+}$traps and crack initiation sites. In addition, the increased work hardening during bending generates dislocations, which act in favour of $\mathrm{H}^{+}$diffusion. Therefore, the existence of greater number of $\mathrm{H}^{+}$traps in combination with various diffusion paths can enhance hydrogen embrittlement and, thus, must be limited.

\section{References}

1. M. R. Louthan Jr. J. Fail. Anal. Prev 8: 289-307(2008).

2. M. Steffen, G. Luxenburger, A. Thieme, A. Demmerath. Dillinger Hütte GTS, Germany.

3. D. G. Stalheim, B. Hoh. Proc. of the $8^{\text {th }}$ Pipeline Conference IPC 2010 (Calgary, Alberta, Canada, October 2010).

4. D. Hejazi, A. J. Haq, N. Yazdipour, D. P. Dunne, A. Calka, F. Barbaro, E. V. Pereloma. Mater. Sci. Eng., A 551 40-49 (2012).

5. Tong-Yi Zhang and Iva Wat. J. Appl. Phys. 93, 6016 (2003)

6. G. T. Park, S. U. Koh, H. G. Jung, K. Y. Kim. Corros. Sci. 50 1865-1871(2008).

7. R. A. Carneiro, R. C. Ratnapuli, V. De Freitas Cunha Lins. Mater. Sci. Eng. A 357 104-110 (2003).

8. S. J. Kim, H. G. Jung, K. Y. Kim. Scripta Mater. 67 895-898 (2012).

9. B. Beidokhti, A. Dolati, A. H. Koukabi. Mater. Sci. Eng. A 507 167-173 (2009).

10. M. Zhao, Y. Shan, F. Xiao, K. Yang, Y. Li. Mater. Lett. 57 141- 145 (2002).

11. Y. H. Kim, J. W. Morris. Metall. Trans. A 14 1883-1888 (1983).

12. CBMM: Sour gas resistant pipe steel, Niobium Information 18/01

13. K. Ravi, V. Ramaswamy, T. K. G. Namboodhiri. Mater. Sci. Eng. A 129 87-97 (1990).

14. Wei Dengy, Xiuhua Gao, Dewen Zhao, Linxiu Du, Di Wu and Guodong Wang J. Mater. Sci. Technol. 26(9) 803-809 2010.

15. S. Papaefthymiou: Hydrogen embrittlement, ELKEME report, 2011, internal communication

16. NACE INTERNATIONAL. NACE TMO284-2016. Test method: Evaluation of pipelines and pressure vessel steels for resistance to hydrogen - induced cracking.

17. ISO 3183. UK : BSI Standards, 2013.

18. M. Maalekian, "The Effects of Alloying Elements on Steels," Technische Universität Graz, 2007. 